\title{
Pemanfaatan Ekstrak Kulit Ubi Jalar Ungu (Ipomea batatas L.) sebagai Bahan Pewarna Alternatif untuk Pengamatan Mikroskopis Paramecium sp. dalam Pembelajaran Biologi
}

\author{
Dewi Fatimatuzahro1, Dian Ayuning Tyas ${ }^{1}$, Saifullah Hidayat ${ }^{1}$ \\ ${ }^{1}$ Program Studi Pendidikan Biologi, Fakultas Sains dan Teknologi, UIN Walisongo Semarang \\ Email: 1imaali43@yahoo.com, 2da.tyas@walisongo.ac.id, ${ }^{3}$ hidayatsaifullah@walisongo.ac.id
}

\begin{abstract}
Purple sweet potato (Ipomea batatas L.) is a tuber that has purple meat and skin. The purple color of purple sweet potato is usually used by the community as a food coloring, while the sweet potato skin is considered only waste and disposed of. This study aims to determine whether purple sweet potato skin extract can be used as an alternative dye on microscopic observations of Paramecium sp. The research used experimental approach with post test only control group design. The process of purple sweet potato skin extraction using chemical solvents is ethanol, acetic acid and water. The extractions with three treatments were $A, B$, and $C$ respectively different ratios (25: 1: 5), (15: 1: 15) and (5: 1:25). The results of microscopic observations quantitatively analyzed using Anova One Way test obtained sign. $>0.05$ which means the purple sweet potato skin extraction results can be used as an alternative dye for microscopic observation of Paramecium sp. Qualitative analysis of the results of observations in which treatment A shows the best dye results in coloring Paramecium sp.
\end{abstract}

Keywords: Extract, purple sweet potato skin, alternative dye, Paramecium sp.

\section{Pendahuluan}

Tanaman ubi jalar (Ipomea batatas L.) merupakan tanaman yang berasal dari benua Amerika. Di Indonesia, 89\% produksi ubi jalar digunakan sebagai bahan pangan dengan tingkat konsumsi 7,9kg/kapita/tahun, sedangkan sisanya dimanfaatkan untuk bahan baku industri terutama saus dan pakan ternak (Qinah 2010). Ubi jalar memiliki warna yang beragam yaitu putih, kuning atau orange dan ungu.

Ubi jalar ungu yang memiliki daging serta kulit yang berwarna ungu mengandung pigmen antosianin dalam jumlah yang cukup besar (Gambar 1). Total kandungan antosianin ubi jalar ungu berkisar 110,51 mg/100 gram. Selain antosianin, ubi jalar ungu juga merupakan sumber antioksidan dan berguna untuk kesehatan (Hambali et al. 2014).

Ubi jalar ungu mengandung vitamin (A, B1, B2, C dan E), mineral (kalsium, kalium, magnesium, tembaga dan seng), serat pangan, serta karbohidrat bukan serat (Ginting et al. 2011).

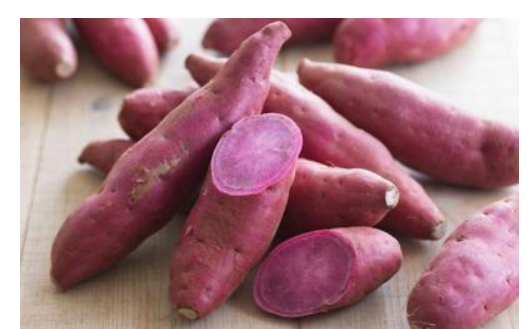

Gambar 1. Ubi jalar ungu (I. batatas L.)

Klasifikasi tanaman ubi jalar (Hambali et al. 2014)

Kingdom : Plantae

Subkingdom : Tracheobionta

Super divisi : :Spermatophyta

Divisi : : : : : :

Kelas : : : : :

Sub Kelas : : Asteridae

Ordo : Solanales

Famili : Convolvulaceae

Genus : Ipomea

Spesies : Ipomea batatas Poir. 
Manfaat ubi jalar ungu salah satunya dapat mengendalikan produksi hormon melatonin yang dihasilkan kelenjar pineal di dalam otak. Melatonin merupakan antioksidan yang menjaga kesehatan sel dan sistem saraf otak, sekaligus memperbaiki jika ada kerusakan.

Antosianin yang terkandung pada umbi serta kulit dari ubi jalar ungu memiliki potensi untuk diekstrak dan dijadikan sebagai pewarna alami. Zat warna menurut asalnya dibedakan menjadi zat warna alami dan zat warna sintetik. Zat warna alami merupakan zat warna yang secara alami terdapat dalam tanaman maupun hewan. Zat warna sintetik merupakan zat warna yang tidak berasal dari tumbuhan maupun hewan, misalnya dari berbagai senyawa kimia yang dapat membentuk suatu zat warna (Winarti et al. 2008). Pembagian zat warna menurut sifatnya dapat dibedakan atas zat warna asam dan zat warna basa (Suntoro 1983).

Cara untuk mendapatkan zat warna dari ubi jalar ungu yaitu salah satunya dengan ekstraksi. Ekstraksi adalah kegiatan penarikan kandungan kimia yang dapat larut sehingga terpisah dari bahan yang tidak dapat larut dengan menggunakan pelarut cair.

Zat warna erat hubungannya dengan proses pewarnaan pada sel atau jaringan. Proses pewarnaan bertujuan agar proses pembedaan sel atau jaringan dapat dilakukan dengan baik (Nurwanti et al. 2013). Pewarnaan bertujuan agar dapat mempertajam dan memperjelas berbagai elemen jaringan, terutama sel-selnya, sehingga dapat dibedakan dan ditelaah dengan mikroskop (Gresby 2013). Proses pewarnaan pada preparat sel dikarenakan adanya reaksi ikatan elektrostatik antara muatan ion zat warna dan bagian sel yang berbeda muatan sehingga jaringan dapat terwarnai. Zat warna yang bersifat basa memiliki muatan ion negatif sedangkan zat warna yang bersifat asam memiliki muatan positif (Bisri et al. 2014). Zat warna memiliki sifat yang berbeda begitupun dengan dengan bagian-bagian dari sel yang memiliki sifat-sifat yang khusus sehingga afinitas bagian-bagian sel tersebut terhadap zat warna juga berbeda (Suntoro 1983). Salah satu contoh organisme dengan bagian-bagian sel yang memiliki sifat yang berbeda adalah Paramecium sp.
Paramecium sp. merupakan protozoa yang termasuk dalam kelas ciliata karena memiliki silia (bulu getar) sebagai alat gerak. Paramecium sp. memiliki bentuk tubuh menyerupai terumpah (sandal). Paramecium sp. hidup di air tawar (Bhamare et al. 2012). Tubuh Paramecium sp. ditutupi oleh lapisan tipis, berlapis ganda dan elastis yang disebut dengan pelikel. Ciri khas Paramecium adalah memiliki vakuola kontraktil. Vakuola kontraktil ini mampu menyimpan dan mengeluarkan air dari tubuh Paramecium (Kastawi et al. 2003). Paramecium sp. memiliki dua inti sel yaitu makronukleus yang berfungsi mengatur kegiatan tubuh seperti bergerak, mencerna makanan (fungsi vegetatif) dan juga mikronukleus yang juga berfungsi mengatur pembiakan (fungsi generatif) (Bhamare et al. 2012).

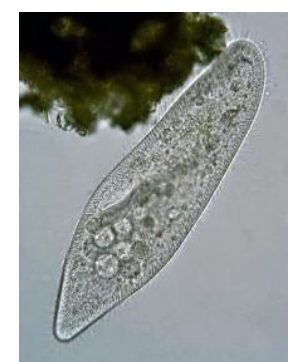

Gambar 2. Paramecium sp.

Klasifikasi Paramecium sp. adalah sebagai berikut (Jahn and Jahn 1949):

Kingdom : Protista

Filum : Ciliophora

Kelas : Ciliata

Ordo : : Peniculida

Famili : Paramecium

Spesies : Paramecium sp.

Hasil penelitian dalam pemanfaatan ekstrak kulit ubi jalar ungu ini digunakan sebagai bahan pewarna alternatif untuk pengamatan mikroskopis Paramecium sp.

\section{Metode}

Pendekatan yang digunakan dalam penelitian ini adalah pendekatan eksperimen. Penelitian dilaksanakan di pasar tradisional Desa Juana Kabupaten Pati, petakan sawah Desa Tawang Rejo Kecamatan Sluke Kabupaten Rembang dan 
Laboratorium Pendidikan Biologi Universitas Islam Negeri Semarang Jawa Tengah.

Populasi dalam penelitian ini adalah koloni Paramecium sp. yang diperoleh dari air sawah desa Tawang Rejo, Kecamatan Sluke, Rembang. Sampel dalam penelitian ini adalah Paramecium sp. yang telah dibiakkan dalam air sawah dan jerami selama dua minggu.

Analisis data dalam penelitian adalah analisis data hasil karakterisasi preparat menggunakan analisis secara kuantitatif serta secara deskriptif melalui hasil pengamatan preparat Paramecium sp. berdasarkan kejelasan preparat dan kekontrasan preparat.

Alat-alat yang digunakan antara lain, gelas Beaker, gelas ukur, corong kaca, pipet tetes, saringan, kertas saring, Mikroskop monokuler, laptop, Optilab, gelas benda, cover glass, water bath, blender, cawan Petri, dan neraca digital. Bahanbahan yang digunakan yaitu, biakan Paramecium sp. (air rendaman jerami), kulit ubi jalar ungu, etanol, asam asetat, metanol, aquades, metilen blue, xilol, alkohol 50\%, alkohol 70\%, alkohol 80\%, alkohol $90 \%$, dan gliserin.

\section{Tahap Ekstraksi Kulit Ubi Jalar Ungu}

a. Ubi jalar ungu dipilih yang bagus kemudian dikupas dan diambil kulitnya.

b. Kulit ubi jalar ungu dicuci kemudian dipotongpotong kecil dan ditimbang seberat $100 \mathrm{gr}$.

c. Kulit dihancurkan dengan blender kemudian ditambahkan pelarut dengan komposisi pelarut yaitu pelarut etanol, asam asetat, air dan menggunakan perbandingan (25:1:5), (15:1 :15) dan (5:1:25) selama 3 menit.

d. Ekstrak yang didapat disaring dengan kain saring/ saringan sehingga menjadi filtrat.

e. Kandungan etanol dari filtrat diuapkan dengan water bath suhu $50^{0} \mathrm{C}$ sehingga didapat filtrat pigmen kental.

f. Filtrat pigmen disaring kembali dengan kertas saring untuk memisahkan endapan sehingga didapat pewarna ubi jalar ungu.

\section{Tahap Pembuatan Preparat Paramecium sp.}

a. Kaca benda dibersihkan dengan alkohol $70 \%$ kemudian dilapisi dengan albumin meyer dan b. ditunggu sampai kering (cara membuat albumin meyer yaitu dengan mencampur putih telur dan gliserin dengan perbandingan $1: 1$ ).

c. Kultur biakan Paramecium sp. diteteskan pada kaca benda sebanyak 1 tetes, ditunggu sampai airnya sebagian menguap dan jangan sampai kering, kemudian difiksasi dengan metanol 2 tetes dan ditunggu sampai kering.

d. Pewarna diteteskan pada preparat sebanyak 5 tetes atau sampai tertutup oleh pewarna selama 5-10 menit.

e. Preparat yang telah diwarnai dicuci dengan aquades selama 2 menit.

f. Preparat didehidratasi dengan alkohol 50\%, $70 \%$, $80 \%$ dan $90 \%$, masing-masing selama 2 menit.

g. Preparat direndam dalam alkohol xilol bertingkat, yaitu dengan perbandingan alkohol: xilol (3:1), (1:1), (1:3) dan 2 kali xilol murni selama selama 2 menit.

$h$. Preparat direkatkan dengan entellan atau kutek kuku dan tutup dengan cover glass.

\section{Tahap Pengamatan Preparat}

Tahap pengamatan preparat dilakukan secara langsung dengan panduan tabel indikator kejelasan preparat dan kekontrasan preparat.

\section{Hasil dan Pembahasan}

Hasil ekstraksi kulit ubi jalar ungu digunakan sebagai eksperimen dan larutan metilen blue sebagai kontrol dijadikan zat pewarna pada preparat protozoa Paramecium sp., kemudian dilakukan pengamatan secara mikroskopis menggunakan mikroskop cahaya monokuler. Hasil pengamatan ditampilkan pada Gambar 3. Karakter kualitatif dan kuantitatif indikator kejelasan dan kekontrasan preparat disajikan pada Tabel 2 dan 3.

\section{Pengamatan Mikroskopis terhadap Preparat Segar Paramecium sp.}

Sampel yang diambil dari air sawah dan ditambahkan dengan jerami padi dan sedikit kotoran ternak sapi dilihat terlebih dahulu dibawah mikroskop. Sampel biakan yang telah dilihat di bawah mikroskop menunjukkan adanya Paramecium sp. yang berkembang. 


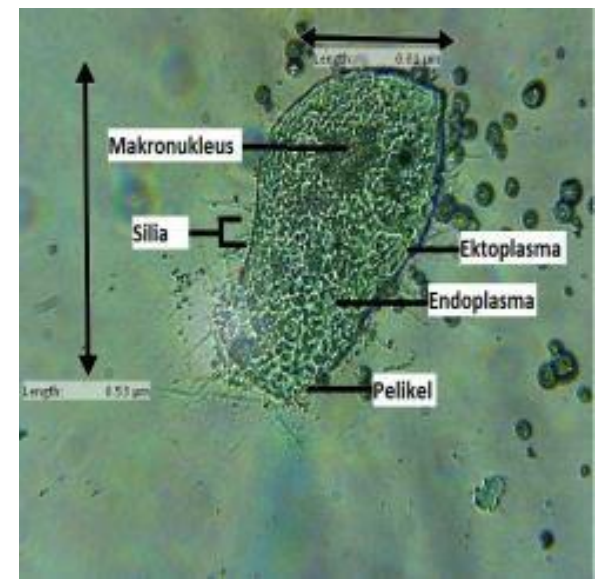

(A)

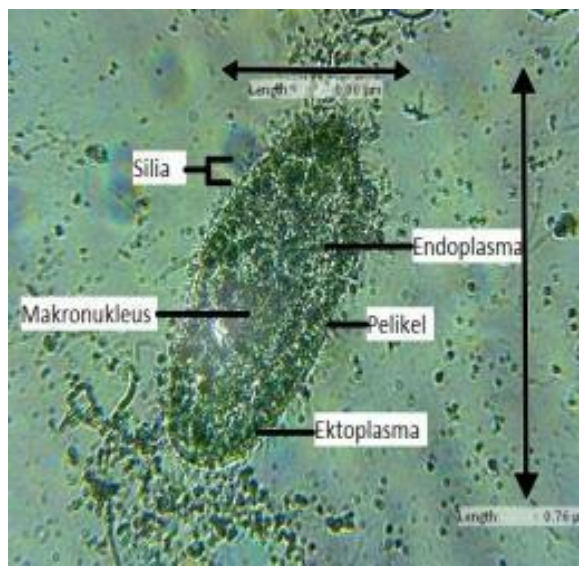

(C)

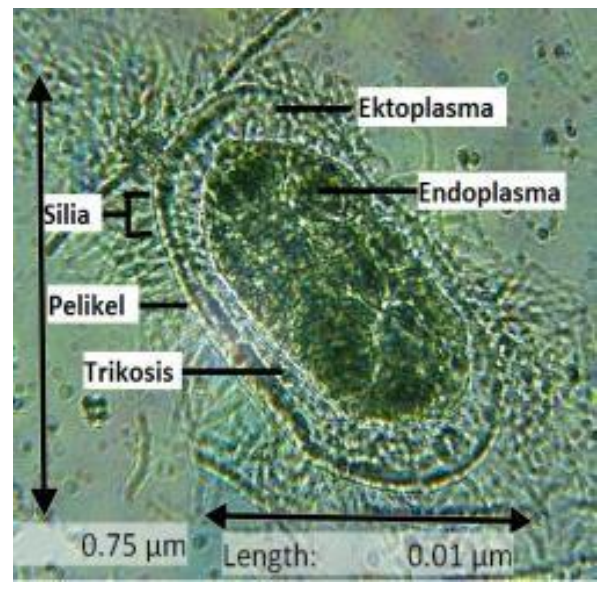

(B)

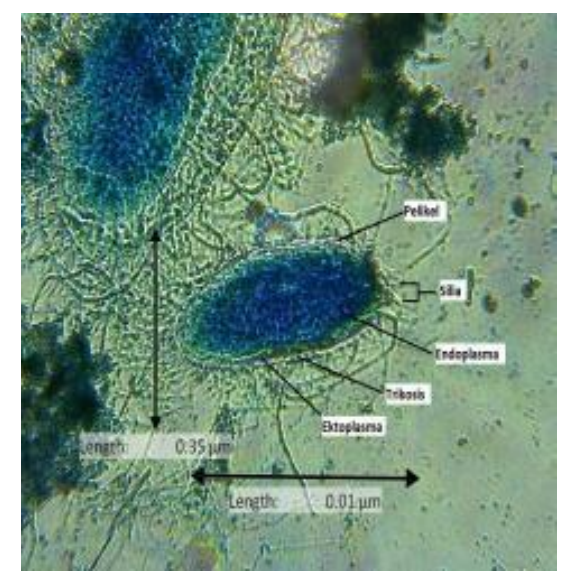

(K)

Gambar 3. Preparat dengan perlakuan A (A), preparat dengan perlakuan B (B), preparat dengan perlakuan C (C), preparat perlakuan kontrol (K)

Tabel 2. Karakter kualitatif preparat mikroskopis Paramecium sp.

\begin{tabular}{ccccc}
\hline No. & Sampel & Perbesaran & Indikator Kejelasan & Indikator Kekontrasan \\
\hline 1 & $1 \mathrm{~A}$ & $400 \mathrm{x}$ & Cukup jelas & Cukup kontras \\
2 & $1 \mathrm{~B}$ & $400 \mathrm{x}$ & Tidak jelas & Tidak kontras \\
3 & $1 \mathrm{C}$ & $400 \mathrm{x}$ & Jelas & Kontras \\
4 & $1 \mathrm{~K}$ & $400 \mathrm{x}$ & Cukup jelas & Cukup kontras \\
5 & $2 \mathrm{~A}$ & $400 \mathrm{x}$ & Jelas & Kontras \\
6 & $2 \mathrm{~B}$ & $400 \mathrm{x}$ & Cukup jelas & Cukup kontras \\
7 & $2 \mathrm{C}$ & $400 \mathrm{x}$ & Cukup jelas & Cukup kontras \\
8 & $2 \mathrm{~K}$ & $400 \mathrm{x}$ & Cukup jelas & Cukup kontras \\
9 & $3 \mathrm{~A}$ & $400 \mathrm{x}$ & Cukup jelas & Cukup kontras \\
10 & $3 \mathrm{~B}$ & $400 \mathrm{x}$ & Cukup jelas & Cukup kontras \\
11 & $3 \mathrm{C}$ & $400 \mathrm{x}$ & Cukup jelas & Cukup kontras \\
12 & $3 \mathrm{~K}$ & $400 \mathrm{x}$ & Cukup jelas & Cukup kontras \\
\hline
\end{tabular}


Tabel 3. Karakter kuantitatif indikator kejelasan dan kekontrasan preparat

\begin{tabular}{ccccc}
\hline No & Preparat & Ulangan & Skor & Persentase \\
\hline 1 & Kontrol & 1 & 2 & \\
2 & Kontrol & 2 & 2 & $66,6 \%$ \\
3 & Kontrol & 3 & 2 & \\
\hline 4 & $\mathrm{~A}$ & 1 & 2 & \\
5 & $\mathrm{~A}$ & 2 & 3 & $77,7 \%$ \\
6 & $\mathrm{~A}$ & 3 & 2 & \\
\hline 7 & $\mathrm{~B}$ & 1 & 1 & \\
8 & $\mathrm{~B}$ & 2 & 2 & $55,5 \%$ \\
9 & $\mathrm{~B}$ & 3 & 2 & \\
\hline 10 & $\mathrm{C}$ & 1 & 3 & \\
11 & $\mathrm{C}$ & 2 & 2 & $77,7 \%$ \\
12 & $\mathrm{C}$ & 3 & 2 & \\
\hline
\end{tabular}

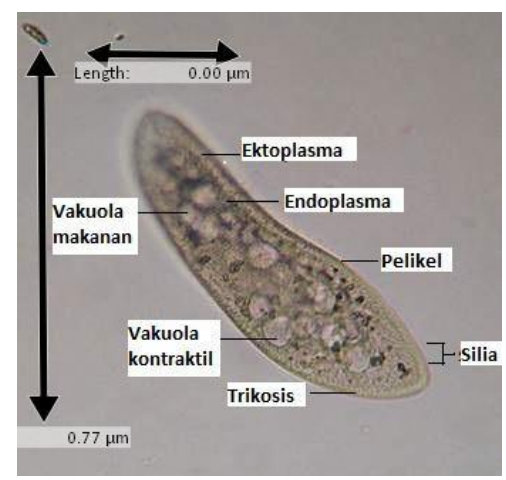

Gambar 4. Paramecium sp. segar

Berdasarkan Gambar 4 sampel preparat segar Paramecium sp., bagian yang dapat diamati adalah sebagai berikut:

a. Silia

Silia berfungsi untuk menyapu partikel makanan kearah mulut serta sangat penting dalam aktivitas pergerakan.

b. Pelikel

Pelikel berfungsi memberikan dukungan dan mempertahankan bentuk organisme.

c. Trikosis

Trikosis berfungsi untuk menangkap mangsa dan dapat digunakan sebagai metode pertahanan.

d. Ektoplasma

Ektoplasma merupakan lapisan sitoplasma bagian terluar.

e. Endoplasma

Endoplasma berisi dua nukleus, banyak vakuola makanan dan vakuola kontraktil. f. Vakuola kontraktil

Vakuola kontraktil berfungsi untuk menyimpan air dan berperan penting dalam proses osmoregulasi.

g. Vakuola makanan

Vakuola makanan berfungsi dalam proses pencernaan dan ekskresi Paramecium sp.

\section{Pengamatan Mikroskopis terhadap Preparat} Paramecium sp. dengan Berbagai Pewarna

Kualitas preparat yang diamati pada semua perlakuan di-skoring berdasarkan tabel indikator kejelasan dan kekontrasan preparat. Data hasil skoring kejelasan dan kekontrasan preparat

Paramecium sp. pada Tabel 2 dan 3 diujii normalitas menggunakan uji kolmogorov-smirnov dan hasilnya diperoleh data normal, maka dilakukan uji beda dengan menggunakan uji One Way Anova.

Tabel 4. Hasil Uji One Way Anova

\begin{tabular}{|l|c|c|c|c|c|}
\hline \multicolumn{1}{|c|}{$\begin{array}{c}\text { Sourch of } \\
\text { Variation }\end{array}$} & SS & Df & MS & $F$ & Sig. \\
\hline Between Groups & .917 & 3 & .306 & 1.222 & .363 \\
\hline Within Groups & 2.000 & 8 & .250 & 1.222 & .363 \\
\hline Total & 2.917 & 11 & & & \\
\hline
\end{tabular}

Hasil uji Anova One Way pada Tabel 4 menunjukkan bahwa 4 perlakuan (Kontrol, A, B dan C) memiliki angka signifikansi $>0,05$. Jika nilai signifikansi > 0,05 maka Ho ditolak dan Ha diterima dan sebaliknya, jika nilai signifikansi $<0,05$ maka Ho diterima dan Ha ditolak. Hasil uji Anova One Way yang dilakukan pada data kuantitatif preparat Paramecium sp. menunjukkan bahwa Ha diterima dan Ho ditolak yaitu ekstrak kulit ubi jalar ungu ( $I$. batatas L.) dapat digunakan sebagai bahan pewarna alternatif untuk pengamatan mikroskopis Paramecium sp. Hasil uji anova untuk semua perlakuan pada menunjukkan bahwa $\mathrm{F}$ hitung sebesar 1,222, sedangkan $F$ tabel untuk level signifikansi 0,05 dengan 12 sampel yaitu sebesar 4,59. Dari data tersebut dapat diketahui bahwa nilai F hitung $<$ F tabel maka Ho diterima dan Ha ditolak. Jika Ho diterima maka tidak terdapat perbedaan yang signifikan antara sampel perlakuan kontrol dengan sampel perlakuan (A, B dan C). 
Preparat semi permanen kemudian dilakukan analisis secara kualitatif dengan membandingkan hasil pengamatan preparat melalui gambar. Preparat semi permanen yang menunjukkan hasil terbaik adalah preparat dengan perlakuan A [perbandingan pelarut yaitu pelarut etanol : asam asetat : air $(25: 1: 5)]$ karena pada preparat perlakuan A organel Paramecium sp. lebih dapat teridentifikasi dengan baik dibandingkan dengan preparat perlakuan B, C dan Kontrol.

Faktor yang mempengaruhi kualitas preparat adalah proses fiksasi serta proses pewarnaan preparat. Proses fiksasi bertujuan untuk mencegah autolisis, mengawetkan jaringan serta mempengaruhi proses pewarnaan. Akan tetapi proses fiksasi yang kurang tepat akan mempengaruhi kualitas preparat seperti sel atau jaringan yang menunggu terlalu lama untuk difiksasi justru akan mengakibatkan sel mengalami plasmolisis.

Faktor selanjutnya adalah faktor proses pewarnaan. Proses pewarnaan melibatkan adanya zat warna. Zat warna mempunyai kemampuan khusus dalam mewarnai jaringan sesuai dengan sifatnya, begitupun dengan bagian-bagian dari sel yang memiliki sifat-sifat yang khusus sehingga afinitas bagian-bagian sel tersebut terhadap zat warna juga berbeda. Zat warna menurut sifatnya dibedakan menjadi zat warna asam dan zat warna basa. Zat warna asam akan mewarnai bagian sel yang bersifat basa dan sebaliknya, zat warna basa akan mewarnai bagian sel yang bersifat asam (Suntoro 1983).

\section{Simpulan}

Berdasarkan hasil penelitian yang dilakukan peneliti menunjukkan bahwa hasil ekstraksi kulit ubi jalar ungu (I. batatas L.) dapat digunakan sebagai pewarna alternatif untuk pengamatan mikroskopis Paramecium sp. berdasarkan hasil perhitungan yang diperoleh yaitu nilai signifikansi > 0,05 yang berarti Ha diterima dan Ho ditolak. Analisis data secara kualitatif menunjukkan bahwa hasil ekstraksi kulit ubi jalar ungu dapat digunakan sebagai pewarna alternatif dengan hasil preparat yang terbaik adalah preparat dengan perlakuan A.

\section{Daftar Pustaka}

Bhamare S. N, Nikam S. V, Jadhav B. N, Dama L. B. 2012. Morphological study of paramecium caudatum from fresh water of nashik district of maharashtra india. Trends in Life Sciences. 1(2): 41-51.

Bisri C, Pantiwati Y, wahyuni S. 2014. Ekstrak kelopak bunga rosella (Hibiscus sabdariffa L.) sebagai pewarnaan alternatif alami preparat section tanaman cabe merah besar (Capsicum annuum L.). Proceeding Biology Education Conference. 11(1): 214-221.

Ginting E, Utomo J. S, Yulifianti R, Jusuf M. 2011. Potensi Ubi Jalar Ungu Sebagai Pangan Fungsional. Iptek Tanaman Pangan. 6(1): 116-138.

Gresby A. K. P. C. 2013. Pemanfaatan filtrat daun jati muda (Tectona grandis) sebagai bahan pewarna alternatif pembuatan preparat maserasi batang cincau rambat (Cyclea barbata). Skripsi. Malang: Universitas Muhammadiyah Malang.

Hambali M, Mayasari F, Noermansyah F. 2014. Ekstraksi antosianin dari ubi jalar dengan variasi konsentrasi solven dan lama waktu ekstraksi. Teknik Kimia. 20(2): 25-35.

Jahn T. L, Jahn F. F. 1949. How to Know the Protozoa. Lowa: W. M. C. Brown Company.

Kastawi Y, Sri E. I, Ibrohim, Masjhudi., Sofia E.R. 2003. Zoologi Avertebrata. Malang: Universitas Negeri Malang.

Nurwanti M, Budiono J. D, Pratiwi R. P. 2013. Pemanfaatan filtrat daun muda jati sebagai bahan pewarna alternatif dalam pembuatan preparat jaringan tumbuhan. BioEdu. 2(1): 73-76.

Qinah E. 2010. Pengaruh Konsentrasi Gula Pasir Dan Tepung Ketan Terhadap Sifat Kimia, Organoleptik Serta Daya Simpan Dodol Ubi Jalar Ungu. Skripsi. Sumatera Utara: Universitas Sumatera Utara. 
Suntoro S. H. 1983. Metode Pewarnaan (Histologi dan Histokimia). Jakarta: Bhratara Karya Aksara.

Winarti S, Sarofa U, Anggrahini D. 2008. Ekstraksi dan stabilitas warna ubi jalar ungu (Ipomea batatas L.) sebagai pewarna alami. Jurnal Teknik Kimia. 3(1): 207-214. 